\title{
Are dietary patterns stable throughout early and mid-childhood? A birth cohort study
}

\author{
Kate Northstone ${ }^{1 *}$ and Pauline M. Emmett ${ }^{2}$ \\ ${ }^{1}$ Department of Social Medicine, University of Bristol, 24 Tyndall Avenue, Bristol BS8 1TQ, UK \\ ${ }^{2}$ Department of Community Based Medicine, University of Bristol, Hampton House, Cotham Hill, Bristol BS6 6JS, UK
}

(Received 5 November 2007 - Revised 25 February 2008 - Accepted 25 February 2008 - First published online 1 April 2008)

This study assesses the stability of dietary patterns obtained using principal components analysis (PCA) through early to mid-childhood. Dietary data were collected from children in the Avon Longitudinal Study of Pregnancy and Childhood (ALSPAC). Frequency of consumption of a range of food items was recorded by mothers using self-completion postal questionnaires when their children were 3, 4, 7 and 9 years of age. Dietary patterns were identified using PCA and component scores were calculated at each time-point. In total 6177 children had data available at all four time-points. Three patterns were consistently seen across time: the 'processed', 'traditional' and 'health conscious' patterns. At 3 years an additional 'snack' pattern was obtained and at 9 years the 'health conscious' pattern was slightly modified (meat products were negatively associated). High correlations were evident for all three scores between each pair of time-points. The widest limits of agreement were seen for all pairings between the 3 and 9 years data, whilst the narrowest were seen between the 4 and 7 years data. A reasonable level of agreement was seen with the categorised component scores from each time-point of data ( $\kappa$ ranging from 0.28 to 0.47 ). Virtually identical dietary patterns were obtained at the ages of 4 and 7; however, periods of change were apparent between the ages of 3 and 4 and the ages of 7 and 9 . It is important to make regular dietary assessments during childhood in order to assess accurately the effects of diet on future health outcomes.

Dietary patterns: Childhood: Principal components analysis: ALSPAC: Diet

The popularity of employing dietary patterns to assess the effects of dietary intake on disease incidence has increased rapidly over recent years. These patterns are increasingly used as an alternative to, or in tandem with, the study of individual nutrients or food intake in epidemiological studies of health risk. Analysis of this kind may overcome the inherent problems of examining individual food and nutrient associations, namely the inter-correlations between these foods and nutrients ${ }^{(1)}$. Currently, the most common method of obtaining dietary patterns is via the method of principal components analysis (PCA). This process identifies the underlying dimensions in a large number of variables based on the inter-correlations between these variables.

It is important to consider the stability of dietary measures used in longitudinal cohort studies. As Weismayer et al. ${ }^{(2)}$ pointed out, the cost of maintaining such cohorts could be reduced if dietary measures proved to be stable over time. The need to collect regular dietary information from cohort members could be reduced if it were shown that there was little variation in dietary patterns, both at a cohort level and at an individual level over time. Knowledge of the stability of dietary patterns over time would also aid researchers in setting up their studies from the outset. If it were known that changes in dietary patterns were evident at or between specific ages, researchers could plan their follow-up times in order to incorporate dietary data collection at such ages. To date, a number of studies have approached this issue in adults and have shown reasonable stability ${ }^{(1,3-12)}$. However, there are inconsistencies between these studies including substantial differences in follow-up times, the number of followup points, sample sizes and different methodologies employed to collect dietary data. Together, these differences make it difficult to draw any firm conclusions about the stability of dietary patterns over time from the published results.

To our knowledge no study has investigated the stability of dietary patterns specifically during childhood. Any changes in patterns may reflect the modification of diet by individuals over time for a number of different reasons. These include: major life events; changes in food preferences or nutritional advice (which is constantly being updated); or by changes in the food supply (e.g. newly available foods such as soy products and probiotics). It is important to assess the effects of any changes in dietary patterns in childhood on health outcomes.

The aim of the present study is to investigate the stability of dietary patterns obtained at four time-points in a cohort study of children, considering patterns scores as both categorical and continuous variables. 


\section{Methods}

The Avon Longitudinal Study of Parents and Children (ALSPAC), an ongoing longitudinal cohort study, was designed to investigate the determinants of development, health and disease during childhood and beyond ${ }^{(13)}$. Eligible participants for the study were those pregnant women with an expected date of delivery between 1 April 1991 and 31 December 1992, who were resident in the former Avon health authority in south-west England. More detailed information on the study can be found on the website (www.alspac.bris.ac.uk). A cohort of 14541 pregnant women was established resulting in 13988 children who were alive at 12 months of age. Ethical approval for the study was obtained from the ALSPAC Law and Ethics committee and the three local research ethics committees.

The present study uses data collected from questionnaires completed when the children were 38, 54, 81 and 103 months of age, these time-points are equivalent to $3 \cdot 2,4 \cdot 5$, 6.8 and 8.6 years, respectively. For ease of reporting we will refer to these time-points as 3, 4, 7 and 9 years of age throughout the paper. All four questionnaires contained a set of questions enquiring about the frequency of consumption of a wide range of foods and drinks. The mother or main carer was given the following options to indicate how often her child was currently consuming a variety of food types 'nowadays': (1) never or rarely; (2) once in 2 weeks; (3) one to three times per week; (4) four to seven times per week; (5) more than once per day. Note that at the ages of 7 and 9 the wording of the questionnaires was slightly different such that the mother was asked about the foods she provided and was asked not to include school dinners, which were asked about separately. Mothers were also asked to record how many cups of tea or coffee, the number of glasses of cola and the number of slices of bread consumed daily. The usual type of bread (white or other) and milk (full-fat or other) usually consumed was also recorded. The data on frequency of consumption were numerically transformed into times consumed per week, in order to apply quantitative meaning to the frequency categories, as follows: (1) 0 ; (2) 0.5 ; (3) 2 ; (4) 5.5 and (5) 10 times per week. All data were standardised by subtracting the mean and dividing by the standard deviation for each variable; this was necessary because tea, coffee, cola and bread were measured on a different scale to the other variables.

The FFQ were adapted from the one used to assess maternal diet at 32 weeks of pregnancy ${ }^{(14)}$. Over time the questionnaires were modified slightly. This was in the light of analysis of data as it became available and changes in the availability of various foods. For example, separate categories were created from the age of 4 , for coated poultry and fish products, vegetarian pies and tuna, which had previously been encompassed in other categories. Therefore, as time progressed, additional foods/drinks were included in the questionnaires (at 3 years ice cream, milk-based puddings, cold meats, meat and vegetarian pies, tinned pasta and nuts were not included, and at 4 years cold meats was not included). We chose to keep this extra information separate in order to maximise the available information, rather than combine into existing food groups created from the earlier questionnaires. The number of food items/groups included in the PCA were 34, 35,41 and 41 at 3, 4, 7 and 9 years of age, respectively.

\section{Statistical methods}

PCA with varimax rotation ${ }^{(15,16)}$ was performed on the standardised food items. Methods for the 3, 4 and 7 years questionnaires have been described in detail elsewhere ${ }^{(17,18)}$. An identical procedure was used for the standardised food items from the 9 years questionnaire. The number of components that best represented the data at each time-point was primarily chosen on the basis of the scree plot ${ }^{(19)}$ and the interpretability of the components. Children were excluded from each PCA if they had more than ten dietary items missing from the respective questionnaire. If ten or fewer items were missing, we made the assumption that the child did not consume those items and they were given a value of 0 . Foods with loadings above $0 \cdot 3$ on a component were considered to have a strong association with that component and were deemed to be the most informative in describing the dietary patterns. Labels were given to each component at each time-point. While these do not perfectly describe each underlying pattern, they aid in the reporting and discussion of the results.

For each child a score was created for each component identified at each time-point by multiplying the factor loadings by the corresponding standardised value for each food and summing across the food items. All component scores were approximately normally distributed. Spearman's correlation coefficients were calculated to measure the associations between the dietary pattern scores obtained at each timepoint. Paired $t$ tests were then applied to assess the change in mean scores between each period of questioning. The $95 \%$ limits of agreement ${ }^{(20)}$ were calculated as the mean difference between each pair of scores plus or minus twice the standard deviation of the differences, enabling us to assess the extent of agreement between the time-points and provide an idea of the spread of the variation of scores between the time-points. In order to make valid comparisons of the limits of agreement across time-points we calculated $z$ scores for each dietary pattern score by subtracting the mean and dividing by the standard deviation. The mean and standard deviation used depended upon which pairwise comparison was being made. For example, when comparing the 'processed' mean scores at 3 and 7 years of age, both these scores were transformed using the 3 years mean and standard deviation for the 'processed' score; when comparing the 4 and 9 years 'traditional' mean scores, the mean and standard deviation for the 4 years scores were used to transform both variables. Standardising using this adjusted method meant that we could express the units of the limits of agreement in terms of standard deviations of the earlier score. Finally, component scores were split into quintiles and weighted $\kappa^{(21)}$ was used to compare scores between each pair of time-points. Weighted $\kappa$ was chosen due to the ordered nature of the categorical data as it takes into account partial agreement between groups.

All analyses were performed using SPSS for Windows version 12.0.1, with the exception of weighted $\kappa$, which were obtained using STATA for Windows version 9.2.

\section{Results}

Table 1 summarises the dietary components that were extracted at each time-point, in the order that they were extracted, together with the proportion of variance that was 
Table 1. Dietary patterns obtained at each time-point in childhood, showing the order of extraction and percentage of variance explained ${ }^{\star}$

\begin{tabular}{|c|c|c|c|c|c|c|c|}
\hline \multicolumn{2}{|c|}{3 years $(n 10139)$} & \multicolumn{2}{|c|}{4 years $(n 9550)$} & \multicolumn{2}{|c|}{7 years $(n 8286)$} & \multicolumn{2}{|c|}{9 years $(n 8010)$} \\
\hline Pattern & $\begin{array}{c}\% \text { Variance } \\
\text { explained }\end{array}$ & Pattern & $\begin{array}{c}\% \text { Variance } \\
\text { explained }\end{array}$ & Pattern & $\begin{array}{l}\% \text { Variance } \\
\text { explained }\end{array}$ & Pattern & $\begin{array}{c}\% \text { Variance } \\
\text { explained }\end{array}$ \\
\hline 'Processed' & $7 \cdot 9$ & 'Processed' & $7 \cdot 3$ & 'Processed' & $7 \cdot 3$ & 'Traditional' & $7 \cdot 9$ \\
\hline 'Health conscious' & $7 \cdot 4$ & 'Traditional' & 6.5 & 'Traditional' & $7 \cdot 0$ & 'Processed' & $7 \cdot 2$ \\
\hline 'Traditional' & $4 \cdot 1$ & 'Health conscious' & 3.9 & 'Health conscious' & $3 \cdot 8$ & $\begin{array}{l}\text { 'Health } \\
\text { conscious/vegetarian' }\end{array}$ & $4 \cdot 1$ \\
\hline
\end{tabular}

${ }^{*}$ For details of subjects and procedures, see Methods.

explained by each component and the number from the cohort with data available. Two patterns were consistently (in terms of the foods loading highly) obtained across time: the 'processed' and 'traditional' patterns. The 'health conscious' pattern was extracted at each time-point but was slightly modified at 9 years of age, where meat products were negatively associated. Table 2 summarises the foods that loaded highly on the patterns at each time-point. It can be seen that the 'processed' pattern was described by foods with high fat and sugar content, and processed and convenience foods. The 'traditional' pattern was highly associated with meat, poultry, potato and vegetable consumption at all time-points. At the ages of 3, 4 and 7 salads, fruit, vegetables, fish, pasta and rice were the foods loading highly on the 'health conscious' pattern. At 8 years of age slight differences were evident. Some of the foods, which loaded highly on the 'health conscious' pattern at earlier ages, loaded highly on the 'traditional' pattern at this age and negative loadings were apparent for poultry, red and cold meats. We therefore chose to label this pattern 'health conscious/vegetarian' but chose to make direct comparisons with the preceding 'health conscious' scores as, overall, the 9 years pattern was closer to the 'health conscious' pattern than the 'traditional' at previous ages.

In total, 6177 children had data available at all four timepoints and the remaining analyses are restricted to this complete case sample. Note that performing PCA at each time-point in this restricted sample did not make any difference to the interpretability of the patterns; there were only minor differences in the factor loadings (data not shown). Table 3 presents the correlations between the dietary patterns at each timepoint. As expected, high correlations were evident for all three scores at each pair of time-points (all $P<0 \cdot 0001$ ). The smallest correlation for these pairwise comparisons was between the 'traditional' components at 3 and 9 years of age $(0 \cdot 35)$. All other correlations were similar in magnitude, falling between 0.41 and 0.69. Little correlation was seen between different patterns across time, with the exception of the "health conscious/ vegetarian' pattern at 9 years of age. This showed a level of negative correlation with the 'traditional' pattern at the preceding time-points, which emphasises the change in the 'health conscious' pattern by 9 years of age.

Since the 'snacks' pattern from the 3 years data was not repeated at any other time-point it was not included in any further comparative analyses.

The mean pattern scores at each time-point are given in Table 4. It can be seen that the mean 'processed' score increased over time. Similar mean scores were evident for the 'health conscious' and 'traditional' patterns at each time-point.
The differences in mean pattern scores between each pair of time-points are shown in Table 5, and compared using paired $t$ tests. There was a consistent increase in the mean 'processed' score at the later ages compared to 3 years (all $P<0.0001$ ). Little difference was seen in the mean 'traditional' or 'health conscious' scores between 3, 4, 7 and 9 years of age.

The narrowest limits of agreement for the adjusted scores were seen for the 'health conscious' pattern between both 3 and 4 years of age and 7 years of age (Table 6), while the widest were seen for all pairings between the 3 and 9 years data. When compared to all other time-point pairings, the limits of agreement between 4 and 7 years of age were the narrowest for each pattern.

A reasonable level of agreement was seen with the categorised component scores from each time-point of data, ranging from 0.25 to 0.47 (Table 7). The lowest levels of agreement were seen with the 'processed' pattern scores between 3 and 9 years $(\kappa 0 \cdot 30)$ and the 'traditional' pattern scores between 3 and 9 years and 4 and 9 years $(\kappa 0.28$ and $0 \cdot 25$, respectively). The levels of agreement between 4 and 7 years of age were between 0.42 and 0.47 .

Given the differences in patterns obtained at 9 years of age compared to previous ages, supplementary analyses were performed to try to determine any general differences in food consumption that may explain the presence of the 'vegetarian' pattern at this time. There were no differences evident in the proportions of children consuming meat, fruit, vegetables or meat substitutes at 7 and 9 years of age (data not shown). There was also no difference in the proportion of children being described as vegetarian by their mothers at these ages.

\section{Discussion}

This paper presents four sets of dietary patterns obtained using PCA in the same cohort of children between 3 and 9 years of age. Two patterns were consistently obtained at each time: the 'processed' and 'traditional' patterns. A 'health conscious' pattern was obtained at the first three time-points while a modified 'health conscious' pattern was obtained at 9 years of age. This loaded highly on many of the foods associated with the previous 'health conscious' patterns but also meat substitutes, pulses, nuts and vegetarian pies were associated. In addition a 'snacks' pattern was only obtained at 3 years of age; cheese, fruit, puddings, cakes, biscuits and crisps loaded highly on this pattern ${ }^{(17)}$, it was originally labelled 'snacks' as the pattern could be described as a diet consisting primarily of snack and finger foods as opposed to foods where cooking is required. 


\begin{tabular}{|c|c|c|c|c|c|c|c|c|c|c|c|c|}
\hline \multirow[b]{2}{*}{ Food item } & \multicolumn{4}{|c|}{ 'Processed' } & \multicolumn{4}{|c|}{ 'Traditional' } & \multicolumn{4}{|c|}{ 'Health conscious' $\dagger$} \\
\hline & 3 years & 4 years & 7 years & 9 years & 3 years & 4 years & 7 years & 9 years & 3 years & 4 years & 7 years & 9 years \\
\hline White bread & $\mathrm{x}$ & - & $\mathrm{x}$ & $\mathrm{x}$ & - & - & - & - & - & - ve $x$ & - & - \\
\hline Non-white bread & - & - & - & - & - & - & - & - & - & $\mathrm{x}$ & $\mathrm{x}$ & - \\
\hline Biscuits & $\mathrm{x}$ & $\mathrm{x}$ & $\mathrm{x}$ & $\mathrm{x}$ & - & - & - & - & - & - & - & - \\
\hline Ice cream & & $\mathrm{x}$ & $\mathrm{x}$ & $\mathrm{x}$ & & - & - & - & & - & - & - \\
\hline Milk-based puddings including custard & & $\mathrm{x}$ & $\mathrm{x}$ & $\mathrm{x}$ & & - & - & $\mathrm{x}$ & & - & - & - \\
\hline Other puddings $\ddagger$ & - & - & - & $\mathrm{x}$ & - & - & - & $\mathrm{x}$ & - & - & - & - \\
\hline Cakes/buns & - & $x$ & $x$ & $\mathrm{x}$ & - & - & - & - & - & - & - & \\
\hline Poultry & - & - & - & - & $x$ & $x$ & $\mathrm{x}$ & $\mathrm{x}$ & - & - & - & - ve $x$ \\
\hline Red meat & - & - & - & - & $\mathrm{x}$ & $\mathrm{x}$ & $\mathrm{x}$ & $\mathrm{x}$ & - & - & - & - ve $x$ \\
\hline Cold meats & & & - & - & & & - & - & & & - & - ve $x$ \\
\hline Coated poultry products & & $x$ & $\mathrm{x}$ & $\mathrm{x}$ & & - & - & - & & - & & - \\
\hline Meat pies & & - & $\mathrm{x}$ & $\mathrm{x}$ & & - & - & - & & - & - & - \\
\hline Sausages, burgers & $\mathrm{x}$ & $\mathrm{x}$ & $\mathrm{x}$ & $x$ & - & - & - & - & - & - & - & - \\
\hline Pizza & $\mathrm{x}$ & $x$ & $\mathrm{x}$ & $\mathrm{x}$ & - & - & - & - & - & - & - & - \\
\hline Fish§ & - & - & - & - & - & $\mathrm{x}$ & - & $\mathrm{x}$ & $\mathrm{x}$ & $\mathrm{x}$ & $x$ & - \\
\hline Eggs & - & - & - & - & - & - & - & $\mathrm{x}$ & $\mathrm{x}$ & - & - & - \\
\hline Cheese & - & - & - & - & - & - & - & - & $\mathrm{x}$ & $\mathrm{x}$ & $x$ & - \\
\hline Vegetarian pies & & - & - & - & & - & - & - & & $\mathrm{x}$ & $\mathrm{x}$ & $\mathrm{x}$ \\
\hline Meat substitutes (soya, tofu etc) & - & - & - & - & - & - & - & - & $\mathrm{x}$ & $\mathrm{x}$ & $\mathrm{x}$ & $\mathrm{x}$ \\
\hline Pulses & - & - & - & - & - & - & - & - & $\mathrm{x}$ & $\mathrm{x}$ & $\mathrm{x}$ & $\mathrm{x}$ \\
\hline Nuts & & - & - & - & - & - & - & - & & $\mathrm{x}$ & $x$ & $\mathrm{x}$ \\
\hline Chips & $\mathrm{x}$ & $\mathrm{x}$ & $\mathrm{x}$ & $\mathrm{x}$ & - & - & - & - & - & - & - & - \\
\hline Roast potatoes & - & - & - & - & $\mathrm{x}$ & $\mathrm{x}$ & $\mathrm{x}$ & $\mathrm{x}$ & - & - & - & - \\
\hline Potatoes (not chips) & - & - & - & - & $\mathrm{x}$ & $\mathrm{x}$ & $\mathrm{x}$ & $\mathrm{x}$ & - & - & - & - ve $x$ \\
\hline Pasta & - & - & - & - & - & - & - & $\mathrm{x}$ & $\mathrm{x}$ & $\mathrm{x}$ & $\mathrm{x}$ & - \\
\hline Rice & - & - & - & - & - & - & - & $\mathrm{x}$ & $\mathrm{x}$ & $\mathrm{x}$ & $\mathrm{x}$ & - \\
\hline Baked beans/tinned pastall & - & $\mathrm{x}$ & $\mathrm{x}$ & $\mathrm{x}$ & - & - & - & - & - & - & - & - \\
\hline Green vegetables & - & - & - & - & $\mathrm{x}$ & $\mathrm{x}$ & $\mathrm{x}$ & $\mathrm{x}$ & - & - & - & - \\
\hline Root vegetables & - & - & - & - & $\mathrm{x}$ & $\mathrm{x}$ & $\mathrm{x}$ & $\mathrm{x}$ & - & - & - & - \\
\hline Peas & - & - & - & - & $\mathrm{x}$ & $\mathrm{x}$ & $\mathrm{x}$ & $\mathrm{x}$ & - & - & - & - \\
\hline Sweetcorn & - & - & - & - & $\mathrm{x}$ & $\mathrm{x}$ & $\mathrm{x}$ & $\mathrm{x}$ & - & - & - & - \\
\hline Salad & - & - & - & - & - & - & - & $\mathrm{x}$ & $\mathrm{x}$ & $\mathrm{x}$ & $\mathrm{x}$ & - \\
\hline Fresh fruit & - & - & - & - & - & - & - & $\mathrm{x}$ & $\mathrm{x}$ & $\mathrm{x}$ & $\mathrm{x}$ & - \\
\hline Fruit juice & - & - & - & - & - & - & - & - & $\mathrm{x}$ & $x$ & - & - \\
\hline Fizzy drinks & $\mathrm{x}$ & $\mathrm{x}$ & $\mathrm{x}$ & $\mathrm{x}$ & - & - & - & - & - & - & - & - \\
\hline Tea/coffee & $\mathrm{x}$ & - & - & - & - & - & - & - & - & - & - & - \\
\hline Water & - & - & - & - & - & - & - & - & $\mathrm{x}$ & - & $\mathrm{x}$ & - \\
\hline Flavoured milk drinks & $\mathrm{x}$ & - & - & - & - & - & - & - & - & - & - & - \\
\hline Sweets & $\mathrm{x}$ & $\mathrm{x}$ & $\mathrm{x}$ & $\mathrm{x}$ & - & - & - & - & - & - & - & - \\
\hline Chocolate & $\mathrm{x}$ & $\mathrm{x}$ & $\mathrm{x}$ & $\mathrm{x}$ & - & - & - & - & - & - & - & - \\
\hline Crisps & $x$ & $\mathrm{x}$ & $\mathrm{x}$ & $\mathrm{x}$ & - & - & - & - & - & - & - & - \\
\hline
\end{tabular}

$\mathrm{X}$, loading $>0.3 ;-$ ve $\mathrm{X}$, loading $<-0.3$; blank cell, data on that food was not collected at that time-point. For details of subjects and procedures, see Methods.

This pattern was labelled 'Health conscious/vegetarian' at 9 years.

$\S$ At 3 years, breaded fish products were included in this group, they were treated separately at all other time-points.

$\|$ At 3 years tinned pasta was not included in this group, as it was not asked about. 
Table 3. Pearson's correlation coefficients between the dietary pattern scores obtained at each time-point in childhood $(n 6177) \dagger$

\begin{tabular}{|c|c|c|c|c|c|c|c|c|c|c|c|c|}
\hline & \multicolumn{4}{|c|}{ 'Processed' } & \multicolumn{4}{|c|}{ 'Traditional' } & \multicolumn{4}{|c|}{ 'Health conscious' } \\
\hline & 3 years & 4 years & 7 years & 9 years & 3 years & 4 years & 7 years & 9 years & 3 years & 4 years & 7 years & 9 years $\ddagger$ \\
\hline \multicolumn{13}{|c|}{ 'Processed' } \\
\hline 3 years & 1 & $0.53^{*}$ & $0.49^{*}$ & $0.46^{*}$ & -0.03 & -0.02 & -0.01 & -0.11 & -0.06 & -0.20 & -0.15 & -0.11 \\
\hline 4 years & & 1 & $0.60^{*}$ & $0.56^{\star}$ & & -0.02 & 0.01 & -0.07 & & -0.05 & -0.11 & -0.08 \\
\hline 7 years & & & 1 & $0.65^{\star}$ & & & -0.03 & -0.11 & & & -0.03 & -0.08 \\
\hline 9 years & & & & 1 & & & & -0.02 & & & & -0.01 \\
\hline \multicolumn{13}{|c|}{ 'Traditional' } \\
\hline 3 years & & & & & 1 & $0.57^{\star}$ & $0.50^{*}$ & $0.35^{*}$ & -0.02 & -0.12 & -0.08 & -0.29 \\
\hline 4 years & & & & & & 1 & $0.61^{*}$ & $0.52^{*}$ & & 0.01 & 0.09 & -0.22 \\
\hline 7 years & & & & & & & 1 & $0.58^{*}$ & & & 0.01 & -0.31 \\
\hline 9 years & & & & & & & & 1 & & & & -0.01 \\
\hline \multicolumn{13}{|c|}{ 'Health conscious' } \\
\hline 3 years & & & & & & & & & 1 & $0.67^{\star}$ & $0.61^{*}$ & $0.41^{*}$ \\
\hline 4 years & & & & & & & & & & 1 & $0.69^{*}$ & $0.52^{*}$ \\
\hline 7 years & & & & & & & & & & & 1 & $0.55^{\star}$ \\
\hline \multicolumn{13}{|l|}{ 'Snacks' } \\
\hline 3 years & -0.01 & 0.27 & 0.21 & 0.21 & -0.01 & 0.02 & 0.03 & 0.08 & -0.01 & 0.09 & 0.08 & 0.03 \\
\hline
\end{tabular}

${ }^{*} P<0.0001$ for the correlations between the same dietary patterns at each pair of time-points.

$\dagger$ For details of subjects and procedures, see Methods.

$\ddagger$ This pattern was labelled 'Health conscious/vegetarian' at 9 years.

We chose to compare the 'health conscious/vegetarian' pattern at 9 years with the 'health conscious' patterns obtained previously. So, for the three patterns that were consistently obtained at each time-point, 'processed', 'traditional' and 'health conscious', there were moderate levels of agreement and stability across the time-points; all correlation coefficients were greater than $0 \cdot 35$. However, the size of the correlations decreased as the time-points became further apart; this suggests that the dietary patterns change gradually over time, which is not surprising as a child's tastes develop. In particular, the 'snack pattern' was only obtained at 3 years of age but was related to the 'processed' pattern obtained at later ages. Moreover, by 9 years of age, the 'heath conscious' pattern had become modified; showing a negative relationship with poultry and meats, while fruit and vegetable eating was more closely associated with the 'traditional' pattern at this age. This change was further emphasised by the negative correlations seen with the 'traditional' pattern scores obtained at preceding time-points. The values of $\kappa$ were smaller for longer time spans (e.g. between 3 and 9 years of age) compared to shorter time spans (e.g. between 7 and 9 years of age). Similarly, the widest limits of agreement were seen for all pairings between the 3 and 9 years data. This suggests greater variability between the 3 and 9 years of age data for this pattern. The narrowest limits of agreement were evident between the 4 and 7 years pairings.

A particular difficulty inherent in attempting to assess the stability of dietary patterns over time lies in the fact that performing separate PCA at each time-point enables the researcher to identify the important patterns at each timepoint. However, it is very difficult to assess the stability of the patterns obtained at earlier time-points if these patterns differ over time, as is the case with the patterns presented here. An alternative approach would be to apply the factor loadings obtained from earlier time-points to the data obtained at later time-points in order to obtain dietary pattern scores. This would enable the researcher to specifically assess the stability of the dietary patterns that were identified at baseline.
However, this method is also limited, as any new patterns that may have emerged at follow-up would not be identified. Indeed, we have shown in the ALSPAC mothers that using this 'applied' method is inappropriate to assess the stability of dietary patterns over time when the dietary patterns are different ${ }^{(12)}$. Nevertheless, in other cohorts this method may be more appropriate, particularly where the follow-up period is relatively short. For example, in adult populations where any changes in patterns cannot be explained by major life events such as pregnancy, illness or moving into a different culture where food availability may differ substantially. We would encourage researchers to investigate both methods when estimating changes and determining what drives the changes in dietary patterns over time obtained using PCA.

There have been conflicting reports of stability in dietary patterns in adults. Mishra et al. ${ }^{(8)}$ reported 'fair-to-moderate' stability in their fruits, vegetables and dairy dietary patterns but poor stability in their meat, potatoes and sweet food pattern over a 17-year period. Borland et al. ${ }^{(11)}$ also reported that their prudent dietary pattern was more stable than their high-energy pattern. Their results suggest that the tracking of healthier eating behaviours is reasonably good. Meanwhile, Van Dam et al. ${ }^{(4)}$ reported that their 'Western' pattern was

Table 4. Mean dietary pattern scores obtained at each time-point in childhood ( $n$ 6177)*

(Mean values and standard deviations)

\begin{tabular}{|c|c|c|c|c|c|c|}
\hline & \multicolumn{2}{|c|}{ 'Processed' } & \multicolumn{2}{|c|}{ 'Traditional' } & \multicolumn{2}{|c|}{$\begin{array}{c}\text { 'Health } \\
\text { conscious' } \dagger\end{array}$} \\
\hline & Mean & (SD) & Mean & (SD) & Mean & (SD) \\
\hline 3 years & -0.13 & 0.93 & -0.01 & 0.99 & 0.01 & 0.99 \\
\hline 4 years & -0.06 & 0.96 & -0.02 & 0.97 & 0.02 & 0.99 \\
\hline 7 years & -0.05 & 0.96 & -0.01 & 0.98 & 0.01 & 0.99 \\
\hline 9 years & -0.03 & 0.98 & -0.02 & 0.98 & 0.01 & 0.98 \\
\hline
\end{tabular}

${ }^{*}$ For details of subjects and procedures, see Methods.

†This pattern was labelled 'Health conscious/vegetarian' at 9 years. 
more highly correlated over 4 and 9 years follow-up compared to the 'prudent' dietary pattern. The study by Mikkila et al. ${ }^{(6)}$, providing the closest comparison to the present study, obtained dietary patterns in their cohort of 3596 children aged 3-18. Follow-up data were collected after 6 and 21 years. Similar dietary patterns were obtained at each timepoint. Considering the younger group of 3-12 year olds, the level of tracking was less compared to the adolescent group aged 15-18 years. It is difficult to make direct comparisons with the results we have presented and these studies due to the different ages examined and the variability in follow-up times. However, the present results are similar to those of Van Dam et al. ${ }^{(4)}$ in that our 'health conscious' score had the lowest correlations and levels of agreement as measured by $\kappa$ over time.

A number of studies have tracked nutrient intakes through early and middle childhood ${ }^{(22,23)}$ but few have examined the tracking of food intakes. Those that have started in middle childhood and followed up into early adolescence showing that fruit, vegetable, milk and fruit juice consumption drops over time, while soft drink/sweetened beverage consumption increases substantially into early adulthood ${ }^{(24,25)}$.

The present sample is substantially larger than many of the studies that have been performed to date in adults. However, as with all cohort studies, there was loss to follow-up. It could be argued that any changes seen in overall dietary pattern scores over time were a result of biases in those who were followed-up. However, as the differences in mean pattern scores are small between time-points that are close together we believe the changes are real and not unduly affected by such bias. A related issue that warrants discussion is that we chose not to repeat the PCA in the sub-sample of 6177 children who had data at all four time-points. All scores derived using PCA have a mean of 0 and a standard deviation of 1 but in Table 4 it can be seen that this is not the case for our dietary pattern scores as we reduced the sample after the PCA had been performed. The mean scores for the 'traditional' and 'health conscious' patterns at all four timepoints were very close to 0 . However, they were slightly more negative for the 'processed' score and for the 3 years time-point in particular. The reduced sample had lower scores overall for this pattern, given the mean score of $-0 \cdot 13$, compared to the original full sample which therefore implies a level of selection bias. The mean scores for the 'processed' pattern are also negative at all future time-points. However, such a consistent pattern was not evident in the other two patterns, suggesting that any effects of selection bias may only be important for the 'processed' pattern. We reported a consistent increase in the mean 'processed' score at the later ages compared to 3 years and given the potential for selection bias these increases might be misleading. Nevertheless, we feel that the most important finding from the current study is that distinctly different patterns were obtained at 3 and 9 years of age compared to those obtained at 4 and 7 years of age. Selection bias is unlikely to have affected the present findings as virtually identical patterns were obtained in the reduced sample of 6177 children compared to those that were obtained in the complete case samples from each time-point.

A further potential limitation of the present study is that dietary intake was assessed using unquantified FFQ as 
Table 6. Mean difference and limits of agreement for adjusted* standardised scores across the dietary pattern scores obtained at each time-point in childhood $(n 6177) \dagger$

\begin{tabular}{|c|c|c|c|c|c|c|}
\hline & \multicolumn{2}{|c|}{4 years } & \multicolumn{2}{|c|}{7 years } & \multicolumn{2}{|c|}{9 years } \\
\hline & Mean difference & Limits of agreement & Mean difference & Limits of agreement & Mean difference & Limits of agreement \\
\hline \multicolumn{7}{|c|}{ ‘Processed' pattern } \\
\hline 3 years & 0.06 & $-1.85,1.96$ & 0.05 & $-1.94,2.05$ & 0.03 & $-2.03,2.09$ \\
\hline 4 years & & & 0.05 & $-1 \cdot 70,1 \cdot 81$ & 0.03 & $-1.83,1.89$ \\
\hline 7 years & & & & & 0.03 & $-1.63,1.68$ \\
\hline \multicolumn{7}{|c|}{ 'Traditional' pattern } \\
\hline 3 years & 0.02 & $-1 \cdot 80,1 \cdot 84$ & 0.01 & $-1.97,1.99$ & 0.02 & $-2 \cdot 28,2 \cdot 32$ \\
\hline 4 years & & & 0.01 & $-1.75,1.75$ & 0.02 & $-1.91,1.96$ \\
\hline 7 years & & & & & 0.02 & $-1.81,1.88$ \\
\hline \multicolumn{7}{|c|}{ 'Health conscious' pattern $\ddagger$} \\
\hline 3 years & -0.02 & $-1.60,1.64$ & 0.00 & $-1.57,1.57$ & -0.01 & $-2 \cdot 14,2 \cdot 16$ \\
\hline 4 years & & & 0.01 & $-1.56,1.57$ & -0.01 & $-1.86,1.88$ \\
\hline 7 years & & & & & -0.01 & $-1.86,1.88$ \\
\hline
\end{tabular}

* Scores for the later time-point in each pair are transformed using the mean and standard deviation of the earlier time-point.

†For details of subjects and procedures, see Methods.

$\ddagger$ This pattern was labelled 'Health conscious/vegetarian' at 9 years.

opposed to a more individualised method such as weighed dietary records. However, studies comparing the results of PCA using FFQ and weighed dietary records ${ }^{(1,4)}$ have found the resulting dietary patterns to be comparable. Finally, mothers were asked at the ages of 7 and 9 to complete the FFQ with regard to the foods that she provided and not to include school dinners. As such there is the possibility of under-reporting of certain foods. However, we do not believe that excluding school dinners when completing the FFQ would have a major impact on the resulting dietary patterns we have obtained. Approximately a quarter of the children were having dinners provided by the school at these timepoints and potential under-reporting would only be in effect if questionnaires were completed during term-time. If such under-reporting were a significant problem it would be expected that the patterns obtained at 4 and 7 years would differ as a result, however, they were virtually identical.

To reiterate the differences found in dietary patterns in childhood, we have reported the presence of a 'snack' pattern at the age of 3 . It is likely that after this age, children are more developed in the foods that they eat and the consumption of finger foods lessens. There was also a change in the 'health conscious' pattern obtained at the age of 9 years. There was no obvious explanation for the modification of this pattern in terms of the frequency of the different kinds of foods that were consumed. Changes in the FFQ did not explain the differences. A 'vegetarian' pattern was identified in the mother's diets during pregnancy and again when their children were 47 months of age ${ }^{(12)}$. It is possible that by 9 years of age, a child's diet has moved more towards that of an adult. It will be important to assess the diet of the children at later ages to determine whether this dietary pattern persists.

It will be important to follow up the present study in a number of ways. By following the children into adolescence; it will be of interest to make more detailed comparisons with other studies that have dietary data available at later ages. The next point of dietary data collected by FFQ in the ALSPAC cohort is at the age of 13 . It will also be of interest to assess those factors that affect intra-individual changes in diet. We have shown that in addition to changes in overall

Table 7. Weighted $\kappa$ for quintiles of dietary pattern scores obtained at each time-point in childhood $(n 6177)^{\star}$

\begin{tabular}{|c|c|c|c|c|c|c|}
\hline & \multicolumn{2}{|c|}{4 years } & \multicolumn{2}{|c|}{7 years } & \multicolumn{2}{|c|}{9 years } \\
\hline & Weighted $\kappa$ & $95 \% \mathrm{Cl}$ & Weighted $\kappa$ & $95 \% \mathrm{Cl}$ & Weighted $к$ & $95 \% \mathrm{Cl}$ \\
\hline \multicolumn{7}{|c|}{ ‘Processed’ pattern } \\
\hline 3 years & 0.36 & $0.35,0.37$ & 0.31 & $0.31,0.32$ & 0.30 & $0.28,0.30$ \\
\hline 4 years & & & 0.42 & $0.42,0.43$ & 0.40 & $0.40,0.41$ \\
\hline 7 years & & & & & 0.47 & $0.45,0.47$ \\
\hline \multicolumn{7}{|c|}{ ‘Traditional' pattern } \\
\hline 3 years & 0.34 & $0.33,0.35$ & 0.34 & $0.33,0.35$ & 0.28 & $0.27,0.28$ \\
\hline 4 years & & & 0.44 & $0.43,0.44$ & 0.25 & $0.23,0.26$ \\
\hline 7 years & & & & & 0.30 & $0.29,0.31$ \\
\hline \multicolumn{7}{|c|}{ 'Health conscious' pattern† } \\
\hline 3 years & 0.43 & $0.42,0.44$ & 0.38 & $0.37,0.39$ & 0.39 & $0.38,0.40$ \\
\hline 4 years & & & 0.47 & $0.46,0.48$ & 0.34 & $0.34,0.35$ \\
\hline 7 years & & & & & 0.44 & $0.43,0.45$ \\
\hline
\end{tabular}

${ }^{*}$ For details of subjects and procedures, see Methods.

†This pattern was labelled 'Health conscious/vegetarian' at 9 years. 
diet, with the loss of the 'snack' pattern after 3 years of age and the modification of the 'health-conscious/vegetarian' pattern by 9 years of age, that there is slight variation in the stability of the consistent patterns over time.

It is apparent from the present study that researchers cannot assume that a cross-sectional measure of diet at one time-point in childhood is relevant to another time-point in childhood. To assess the impact of diet on the development of disease it is important to take repeated measures of diet, at least throughout early to mid-childhood. However, this is not always possible, primarily due to financial restraints. Based on the results presented here there appear to be differences in the dietary patterns obtained over a 5-year period, from early childhood at age 3 through to mid-childhood at age 9. However, these differences were relatively small between each pair of consecutive time-points, in particular between the ages of 4 and 7 years although this period was the longest. The dietary patterns obtained at these two time-points were virtually identical in terms of the factor loadings and hence the patterns obtained and it may be reasonable to suggest that data collection at one point between the ages of 4 and 7 would suffice.

\section{Acknowledgements}

We are extremely grateful to all the families who took part in this study, the midwives for their help in recruiting them, and the whole ALSPAC team, which includes interviewers, computer and laboratory technicians, clerical workers, research scientists, volunteers, managers, receptionists and nurses. The UK Medical Research Council, the Wellcome Trust and the University of Bristol provide core support for ALSPAC. This work was also partially funded by a Wellcome Trust VIP award to K. N. and by the Arthritic Association supporting K. N. and P. M. E. This publication is the work of the authors who also serve as guarantors for the contents of this paper; we declare there is no conflict of interest.

\section{References}

1. Hu FB, Rimm E, Smith-Warner SA, Feskanich MJ, Stampfer MJ, Ascherio A, Sampson L \& Willett WC (1999) Reproducibility and validity of dietary patterns assessed with a food-frequency questionnaire. Am J Clin Nutr 69, 243-249.

2. Weismayer C, Anderson JG \& Wolk A (2006) Changes in the stability of dietary patterns in a study of middle-aged Swedish women. J Nutr 136, 1582-1587.

3. Prevost AT, Wichelow MT \& Cox BD (1997) Longitudinal dietary changes between 1984-5 and 1991-2 in British adults: associations with socio-demographic, lifestyle and health factors. Br J Nutr 78, 873-888.

4. Van Dam RM, Rimm EB, Willett WC, Stampfer MJ \& Hu FB (2002) Dietary patterns and the risk for Type 2 Diabetes Mellitus in US men. Ann Intern Med 136, 201-209.

5. Khani BR, Ye W, Terry P \& Wolk A (2004) Reproducibility and validity of major dietary patterns among Swedish women assessed with a food-frequency questionnaire. J Nutr 134, 1541-1545.

6. Mikkila V, Rasanen L, Raitakari OT, Pietinen P \& Viikari J (2005) Consistent dietary patterns identified from childhood to adulthood: the cardiovascular risk in young Finns Study. $\mathrm{Br} J$ Nutr 93, 923-931.

7. Cuco G, Fernandez-Ballart J, Sala J, Viladrich C, Iranzo R, Vila J \& Arija V (2006) Dietary patterns and associated lifestyles in preconception, pregnancy and postpartum. Eur J Clin Nutr 60, 364-371.

8. Mishra G, McNaughton SA, Bramwell GD \& Wadsworth MEJ (2006) Longitudinal changes in dietary patterns during adult life. Br J Nutr 96, 735-744.

9. Newby P, Weismayer C, Akesson A, Tucker K \& Wolk A (2006) Longitudinal changes in food patterns predict changes in weight and body mass index and the effects are greatest in obese women. J Nutr 136, 2580-2587.

10. Schulze M, Fung T, Manson J, Willett W \& Hu F (2006) Dietary patterns and changes in body weight in women. Obesity 14, 1444-1453.

11. Borland SE, Robinson SM, Crozier SR, Inskip HM \& SWS Study Group (2007) Stability of dietary patterns in young women over a 2-year period. Eur J Clin Nutr 62, 119-126.

12. Northstone K \& Emmett PM (2007) A comparison of methods to assess changes in dietary patterns from pregnancy to 4 years post-partum obtained using principal components analysis. $\mathrm{Br} J$ Nutr (Epublication ahead of print version 5 October 2007).

13. Golding J, Pembrey M, Jones R \& ALSPAC Study Team (2001) ALSPAC - The Avon Longitudinal Study of Parents and Children. I. Study methodology. Paediatr Perinat Epidemiol 15, $74-87$.

14. Rogers IS, Emmett PM \& the ALSPAC Study Team (1998) Diet during pregnancy in a population of pregnant women in South West England. Eur J Clin Nutr 52, 246-250.

15. Gorsuch RL (1974) Factor Analyses. Philadelphia: W.B. Saunders.

16. Kline P (1994) An Easy Guide to Factor Analysis. London: Routledge.

17. North K, Emmett P \& the ALSPAC Study Team (2000) Multivariate analysis of diet among three-year old children and associations with socio-demographic characteristics. Eur $J$ Clin Nutr 54, 73-80.

18. Northstone K, Emmett P \& the ALSPAC Study Team (2005) Multivariate analysis of diet in children at four and seven years of age and associations with socio-demographic characteristics. Eur J Clin Nutr 59, 751-760.

19. Cattell RB (1966) The scree test for the number of factors. Multivariate Behav Res 1, 245-276.

20. Bland JM \& Altman DG (1986) Statistical methods for assessing agreement between two methods of clinical measurement. Lancet i, 307-310.

21. Cohen J (1968) Weighted kappa: nominal scale agreement with provision for scaled disagreement or partial credit. Psychol Bull 70, 213-220.

22. Boulton TJ, Magarey AM \& Cockingron RA (1995) Tracking of serum lipids and dietary energy, fat and calcium intake from 1 to 15 years. Acta Paediatr 84, 1050-1055.

23. Singer MR, Moore LL, Garrahie EJ \& Ellison RC (1995) The tracking of nutrient intake in young children: the Framingham Children's Study. Am J Public Health 85, 1673-1677.

24. Lytle LA, Seifert S, Greenstein J \& McGovern P (2000) How do children's eating patterns and food choices change over time? Results from a cohort study. Am J Health Promot 14, 222-228.

25. Demory-Luce D, Morales M, Nicklas T, Baranowski T, Zakeri I \& Berenson G (2004) Changes in food group consumption patterns from childhood to young adulthood: the Bogalusa Heart Study. J Am Diet Assoc 104, 1684-1691. 